\title{
ANÁLISE MULTIVARIADA E VARIABILIDADE ESPACIAL NA ESTIMATIVA DA ERODIBILIDADE DE UM ARGISSOLO VERMELHO-AMARELO ${ }^{(1)}$
}

\author{
Daniela Popim Miqueloni ${ }^{(2)}$ \& Célia Regina Paes Bueno ${ }^{(3)}$
}

\begin{abstract}
RESUMO
A erodibilidade é um fator de extrema importância na caracterização da perda de solo, representando os processos que regulam a infiltração de água e sua resistência à desagregação e o transporte de partículas. Assim, por meio da análise de dependência espacial dos componentes principais da erodibilidade (fator $\mathrm{K}$ ), objetivou-se estimar a erodibilidade do solo em uma área de nascentes da microbacia do Córrego do Tijuco, Monte Alto-SP, e analisar a variabilidade espacial das variáveis granulométricas do solo ao longo do relevo. A erodibilidade média da área foi considerada alta, e a análise de agrupamento k-means apontou para uma formação de cinco grupos: no primeiro, os altos teores de areia grossa (AG) e média (AM) condicionaram sua distribuição nas áreas planas; o segundo, caracterizado pelo alto teor de areia fina (AF), distribui-se nos declives mais convexos; o terceiro, com altos teores de silte e areia muito fina (AMF), concentrou-se nos maiores declives e concavidades; o quarto, com maior teor de argila, seguiu as zonas de escoamento de água; e o quinto, com alto teor de matéria orgânica (MO) e areia grossa (AG), distribui-se nas proximidades da zona urbana. A análise de componentes principais (ACP) mostrou quatro componentes com $87,4 \%$ das informações, sendo o primeiro componente principal (CP1) discriminado pelo transporte seletivo de partículas principalmente em zonas pontuais de maior declividade e acúmulo de sedimentos; o segundo (CP2), discriminado pela baixa coesão entre as partículas, mostra acúmulo da areia fina nas áreas de menor cota em toda a área de concentração de água; o terceiro (CP3), discriminado pela maior agregação do solo, concentra-se principalmente nas bases de grandes declives; e o quarto (CP4), discriminado pela areia muito fina, distribui-se ao longo das declividades nas maiores altitudes. Os resultados sugerem o comportamento granulométrico do solo, que se mostra suscetível ao processo erosivo devido às condições texturais superficiais e à movimentação do relevo.
\end{abstract}

Termos de indexação: componentes principais, análise de agrupamento, krigagem, erosão.

\footnotetext{
(1) Parte da Dissertação de Mestrado do primeiro autor apresentada ao Programa de Pós-Graduação em Ciência do Solo da Faculdade de Ciências Agrárias e Veterinárias - FCAV/UNESP. Recebido para publicação em 7 de maio de 2010 e aprovado em 7 de maio de 2011.

(2) Mestranda do Departamento de Solos e Adubos da Faculdade de Ciências Agrárias e Veterinárias - FCAV/UNESP. Via de Acesso Paulo Donato Castellane s/n, CEP 14884-900 Jaboticabal (SP). Bolsista CAPES. E-mail: danimique@yahoo.com.br

(3) Professora Doutora do Departamento de Solos e Adubos, FCAV/UNESP. E-mail: crbueno@fcav.unesp.br
} 


\title{
SUMMARY: MULTIVARIATE ANALYSIS AND SPATIAL VARIABILITY TO ESTIMATE SOIL ERODIBILITY OF AN ANFISOL
}

\begin{abstract}
Erodibility is an important factor for soil loss quantification, representing the processes that regulate water infiltration and soil resistance to the breakdown and transport of particles. Thus, by analyzing the spatial dependence of the principal components of erodibility (Kfactor), aimed to estimate soil erodibility in a headwaters area in the watershed Córrego do Tijuco, Monte Alto, SP, and analyze the spatial variability of soil texture variables across the landscape. The mean erodibility of the area was high and the analysis of k-means clustering indicated the formation of five groups: the first high, with coarse (AG) and intermediate sand was distributed in the plane areas, the second with high content of fine sand (AF), was distributed in more convex slopes, and the third, with high levels of silt and very fine sand, was concentrated on steeper slopes and in hollows, the fourth with highest clay content, was concentrated in drainage areas, and the fifth, with high content of organic matter (MO) and coarse sand was distributed near the urban area. The principal component analysis (PCA) showed four components with $87.4 \%$ of the information. The first principal component (PC1) discriminated the selective transport of particles, mainly in specific areas of greatest slope and sediment buildup, the second component (PC2) discriminated the low cohesion between the particles, shows accumulation of fine sand at lower altitudes of the entire area of water concentration, the third component (PC 3) discriminated the greatest soil aggregation, mainly at the bases of high slopes and the fourth component (PC4) discriminated very fine sand, distributed along the slope at higher elevations. The results indicate the behavior of soil granulometry, which appears susceptible to erosion due to the surface textural conditions and the relief movement.
\end{abstract}

Index terms: Principal components, cluster analysis, kriging, erosion.

\section{INTRODUÇÃO}

O comportamento dos solos em relação à erosão depende, além de outros fatores, de suas características inerentes. O fator erodibilidade do solo reflete essas propriedades, como resultado das características físicas de textura, estrutura, agregação e porosidade (Toy et al., 2002). Entre estas encontram-se principalmente as que alteram a velocidade de infiltração, permeabilidade e capacidade de armazenamento, resistência a forças de dispersão, abrasão e transporte pelo escoamento superficial (Bertoni \& Lombardi Neto, 2008), atuando na Equação Universal da Perda de Solo como a integração do impacto da gota de chuva e do escoamento superficial sobre a perda para um dado tipo de solo (Haan et al., 1994).

Essas interações inerentes ao processo erosivo devem ser analisadas e compreendidas de acordo com as características pontuais de cada área, o que possibilita alternativas de controle e mitigação do problema de acordo com as possibilidades locais. Um dos caminhos para o entendimento dessas interações é a interpretação da variabilidade espacial da erodibilidade, que varia significativamente de um local para outro conforme suas características físicas e depende, em termos geoestatísticos, do tamanho da área amostrada e da escala de observação, resultando em valores de dependência espacial maiores quanto maior for o intervalo entre as medidas (Trangmar et al., 1985), expandindo a análise para áreas mais extensas, uma vez que a estacionaridade considera todas as amostras pertencentes a populações com os mesmos momentos estatísticos (Vieira, 2000). Além disso, a manutenção de valores atípicos, que se encontram no intervalo usual das variáveis, pode garantir a maior parte da variabilidade da população, pois, apesar de serem únicos em sua combinação de valores, ainda representam um segmento válido da população (Hair et al., 2005).

Dessa forma, os objetivos deste estudo foram estimar a erodibilidade do solo em uma área de nascentes e analisar a variabilidade espacial das variáveis granulométricas do solo ao longo do relevo, na tentativa de compreender seu comportamento na área.

\section{MATERIAL E MÉTODOS}

A principal área de nascentes da microbacia do Córrego do Tijuco situa-se no município de Monte AltoSP e pertence à sub-bacia do Rio Mogi-Guaçu no nordeste do Estado. Localizada na zona do Planalto de Monte Alto, entre 410 e $740 \mathrm{~m}$ de altitude, é constituída por arenitos da Formação Adamantina e Marília, do Grupo Bauru (IPT, 1981). Os solos predominantes pertencem à classe dos Argissolos Vermelho-Amarelos eutróficos, com ou sem caráter abrúptico, textura arenosa/média ou média, relevo suave ondulado e ondulado (Figura 1), horizonte A moderado (Embrapa, 2006). O clima é classificado 
segundo Köppen como mesotérmico de inverno seco (Cwa), com precipitações pluviais anuais que variam entre 1.100 e $1.700 \mathrm{~mm}$, e a temperatura média anual é de $20^{\circ} \mathrm{C}$. No uso e ocupação da área, destaca-se o cultivo agrícola, principalmente cana-de-açúcar, seguido de pastagem e cultivo de frutas e hortaliças, além da zona urbana.

Com a finalidade de determinar a granulometria, foram coletadas 239 amostras de solo georreferenciadas a partir de uma malha regular de $250 \mathrm{~m}$ de distância entre os pontos, na profundidade de 0 a $0,20 \mathrm{~m}$, em uma área de 1.540 ha, no mês de junho de 2009. As amostras foram secas ao ar, destorroadas e passadas em peneira com malha de $2 \mathrm{~mm}$ de abertura. A análise granulométrica das amostras foi realizada pelo método da pipeta, por meio da dispersão com $\mathrm{NaOH}$ $0,1 \mathrm{~mol} \mathrm{~L}^{-1}$ e agitação lenta por 16 horas (Day, 1965). As frações de partículas maiores que $0,1 \mathrm{~mm}$ foram separadas por peneiramento (peneira de 0,105 $\mathrm{mm}$ ), e as frações de tamanho menor, por sedimentação, segundo a lei de Stockes, e fracionamento composto da areia. A quantificação da matéria orgânica foi feita pelo método colorimétrico (Cantarella et al., 2001).

A quantificação da erodibilidade do solo foi estimada pelo cálculo do fator $\mathrm{K}$, consistindo em um modelo matemático expresso em $\mathrm{Mg} \mathrm{h} \mathrm{MJ}^{-1} \mathrm{~mm}^{-1}$, de acordo com o proposto por Denardin (1990):

$$
\begin{gathered}
\mathrm{K}=7,48 \cdot 10^{-6} \mathrm{M}+4,48059 \cdot 10^{-3} \mathrm{P}-6,31175 \cdot 10^{-2} \\
\mathrm{DMP}+1,039567.10^{-2} \mathrm{R}
\end{gathered}
$$

em que $\mathrm{M}(\%)=($ areia muito fina + silte $) \times($ areia muito fina + silte + areia muito grossa + areia grossa + areia média + areia fina); $\mathrm{P}=$ valor da permeabilidade, determinado pelos valores: $1=$ muito rápida, $2=$ rápida, $3=$ moderada, $4=$ lenta, $5=$ muito lenta, $6=$ imperfeitamente drenado; DPM = diâmetro médio ponderado das partículas de solo menores que $2 \mathrm{~mm}$, expresso em mm; e R = [(areia muito grossa + areia grossa + areia média + areia fina) (teor de matéria orgânica/100)].

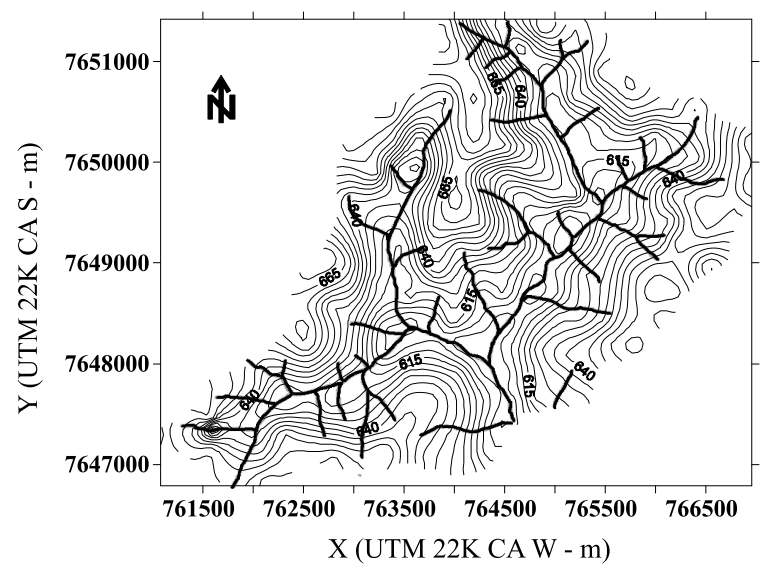

Figura 1. Mapa planialtimétrico e rede de drenagem da área estudada (Datum: UTM 22K Córrego Alegre Sul).
Os dados obtidos foram analisados por meio da estatística descritiva, referentes às medidas de tendência central e variabilidade para as estimativas de erodibilidade, granulometria e matéria orgânica, e as análises de agrupamento e componentes principais, realizadas no programa Statistica 7.0. A análise de agrupamento é utilizada com o objetivo de encontrar padrões no conjunto de dados, a fim de agrupá-los de acordo com as semelhanças entre amostras, de modo que exista o máximo de distinção entre os grupos. A análise de componentes principais (ACP) é considerada uma técnica de interdependência, em que as variáveis não são definidas como dependentes ou independentes, pois são analisadas simultaneamente, sendo aplicada às variáveis granulométricas e matéria orgânica, considerando como variável suplementar o fator K, com valores padronizados, resultando em média nula e variância unitária (Hair et al., 2005). A padronização dos dados garante a consistência da técnica, uma vez que as medidas de distância são sensíveis a diferenças de escalas ou magnitudes das variáveis. A ACP foi utilizada com o intuito de visualizar a distribuição dos fatores no plano bidimensional formado por componentes principais (CP), bem como analisar o poder discriminatório dos fatores de perda de solo em cada componente principal, conforme:

$$
\mathrm{r}_{j}\left(\mathrm{CP}_{h}\right)=\frac{\mathrm{a}_{j h} \sqrt{\lambda_{h}}}{\mathrm{~s}_{j}}
$$

em que $\mathrm{r}_{\text {fatorj }}\left(\mathrm{CP}_{h}\right)=$ correlação da variável $j$ (fator de perda de solo) com o $h$-ésimo componente principal; $\mathrm{s}_{j}=$ desvio-padrão da variável $j ; \mathrm{a}_{i j}=$ coeficiente da variável $j$ no h-ésimo componente principal; e $\lambda_{h}=$ autovalor $h$.

Os autovetores $\left(\mathrm{CP} 1, \mathrm{CP} 2, \ldots, \mathrm{CP}_{h}\right)$ foram construídos a partir dos autovalores da matriz de covariância dos fatores da perda de solo em ordem decrescente, em que o CP1 é o componente que retém a maior variabilidade do conjunto original dos dados, enquanto o último componente retém a menor. A variância retida em cada componente principal pode ser calculada da seguinte forma:

$$
C P_{h}=\frac{\lambda_{h}}{\operatorname{traço}(C)} \times 100
$$

em que $\mathrm{CP}_{h}=$ componente principal $h ; \lambda_{h}=$ autovalor $h ; \mathrm{C}=$ matriz de covariância; e traço $(\mathrm{C})=\lambda_{1}+\lambda_{2}+\ldots+$ $\lambda_{h}$.

A dependência espacial entre as amostras foi avaliada para cada componente principal pelos respectivos escores por meio da geoestatística, com a geração dos semivariogramas com o auxílio do software GS+ 7.0, e os mapas de isolinhas, gerados por krigagem em blocos 2 × 2, com base na pressuposição de estacionariedade da hipótese intrínseca (Vieira, 2000), a qual é estimada por:

$$
\gamma(h)=\frac{1}{2 N(h)} \sum_{i=l}^{N(h)}\left[Z\left(x_{i}\right)-Z\left(x_{i}+h\right)\right]^{2}
$$


em que $N(h)=$ número de pares de observações $Z\left(x_{i}\right)$ e $Z\left(x_{i}+h\right)$ separados por uma distância $h$.

O gráfico de $\gamma(h)$ pela distância $h$ é denominado semivariograma - base para a determinação dos mapas de isolinhas, delineados no programa Surfer 8.0, com datum Córrego Alegre Sul em UTM fuso 22. O ajuste e a seleção dos modelos dos semivariogramas foram realizados com base na menor soma de quadrados do resíduo, no maior coeficiente de determinação e no melhor desempenho da validação cruzada (Zimback, 2001).

\section{RESULTADOS E DISCUSSÃO}

A estatística descritiva das variáveis granulométricas e de matéria orgânica que compõem a erodibilidade pode ser observada no quadro $1 . \mathrm{Na}$ análise granulométrica não foi detectada a fração areia muito grossa. Apenas areia média (AM), areia fina (AF) e areia muito fina (AMF) apresentaram comportamento normal de acordo com o teste de Kolmogov-Smirnov a $5 \%$. Souza et al. (2003), em Latossolos no município de Jaboticabal-SP, encontraram distribuição normal para areia muito grossa, silte, matéria orgânica e fator $\mathrm{K}$, tendo este último também distribuição normal para Souza et al. (2005), no mesmo tipo de solo, em Guariba-SP.

A erodibilidade do solo (fator $\mathrm{K}$ ) média foi de $0,036 \mathrm{Mg} \mathrm{h} \mathrm{MJ}^{-1} \mathrm{~mm}^{-1}$, considerada alta por Bertoni \& Lombardi Neto (2008). Silva (2008) determinou $0,042 \mathrm{Mg} \mathrm{h} \mathrm{MJ} \mathrm{Jm}^{-1} \mathrm{~mm}^{-1}$ para a mesma classe de solos de Sorocaba-SP, e Bueno \& Stein (2004) observaram $0,0438 \mathrm{Mg} \mathrm{h} \mathrm{MJ}-1 \mathrm{~mm}^{-1}$ para Brotas-SP. A erodibilidade apresenta maior influência na determinação da perda de solo principalmente em áreas oriundas de solos com horizonte subsuperficial com acúmulo de argila (Bertoni \& Lombardi Neto, 2008). As características inerentes aos solos, como teor de argila, silte e areia, interferem de forma significativa no comportamento do solo em relação à erosão, tornando os solos com horizonte B textural mais suscetíveis que os B latossólicos (Toy et al., 2002).

O resultado da análise não hierárquica de agrupamento k-means gerou o perfil construído com os centroides de cada grupo, discriminando suas características (Figura 2).

Considerando apenas os elementos de menor distância, foram formados cinco grupos, caracterizados pela presença ou ausência dos teores das variáveis granulométricas e por sua distribuição ao longo do relevo, de acordo com as informações planialtimétricas do local (Figura 1). O grupo 1 aparece com altos teores de areia média e grossa e menores teores de argila, silte e matéria orgânica, distribuindo-se nas áreas mais planas e de maior altitude. O grupo 2 apresentou altos teores de areia fina, aparecendo em áreas de declive suave, principalmente lineares. O grupo 3 destaca-se nos teores de silte e areia muito fina e nos teores muito baixos de areia média, concentrando-se nas áreas mais declivosas e côncavas. Resultados

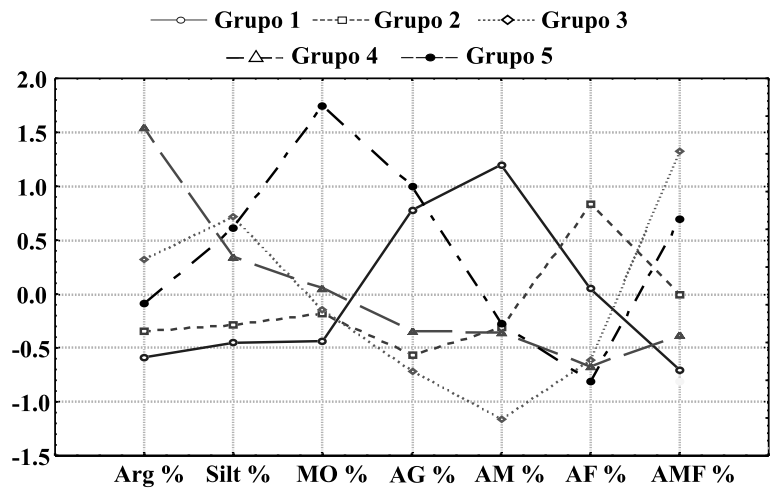

Figura 2. Gráfico do perfil de centroides de cada grupo formado a partir da percentagem das variáveis determinadas: argila (Arg), silte (Silt), matéria orgânica (MO), areia grossa (AG), areia média (AM), areia fina (AF) e areia muito fina (AMF).

Quadro 1. Estatística descritiva para as variáveis argila, silte, matéria orgânica (MO), areia grossa (AG), areia média (AM), areia fina (AF), areia muito fina (AMF) e fator $\mathrm{K}$

\begin{tabular}{|c|c|c|c|c|c|c|c|c|}
\hline Variavel & Média & Mediana & $\mathbf{S}$ & Var & CV & CA & CR & KS \\
\hline Argila $^{(1)}$ & 13,44 & 12,40 & 5,41 & 29,22 & 40,21 & 1,00 & 1,50 & 0,095 \\
\hline Silte $^{(1)}$ & 5,82 & 5,20 & 3,02 & 9,11 & 51,86 & 2,93 & 14,45 & 0,135 \\
\hline $\mathrm{MO}^{(1)}$ & 0,90 & 0,79 & 0,49 & 0,24 & 54,84 & 2,01 & 6,98 & 0,131 \\
\hline $\mathrm{AG}^{(1)}$ & 1,96 & 1,80 & 1,31 & 1,71 & 66,53 & 1,45 & 3,35 & 0,093 \\
\hline $\mathrm{AM}^{(1)}$ & 18,43 & 18,00 & 5,52 & 30,46 & 29,94 & 0,44 & 0,66 & $0,066^{*}$ \\
\hline $\mathrm{AF}^{(1)}$ & 41,89 & 42,00 & 5,76 & 33,13 & 13,74 & $-0,70$ & 2,29 & $0,062^{*}$ \\
\hline $\mathrm{AMF}^{(1)}$ & 18,54 & 18,30 & 4,64 & 21,52 & 25,02 & 0.10 & $-0,01$ & $0.039 *$ \\
\hline Fator $\mathbf{K}^{(2)}$ & 0,04 & 0,02 & 0,05 & $4,75 \mathrm{E} 7$ & 146,06 & 6,01 & 44,53 & 0,230 \\
\hline
\end{tabular}

Número de amostras para as variáveis: N: 239; S: desvio-padrão; Var: variância; CV: coeficiente de variação; CA: coeficiente de assimetria; CR: curtose; KS: teste de normalidade de Kolmogov-Smirnov; *: não significativo a 5 \%; 1. unidade em \%; 2 . unidade em $\mathrm{Mg} \mathrm{h} \mathrm{MJ} \mathrm{Mm}^{-1}$. 
semelhantes para areia foram observados por Leão et al. (2010), que obtiveram maior teor de areia grossa e areia média nas áreas de maior cota e areia fina no sopé de encostas, e Souza et al. (2003) encontraram maior variabilidade das partículas mais finas em inclinações mais lineares. A presença de partículas de areia mais finas nas zonas de acúmulo de sedimento e de partículas maiores nas áreas mais elevadas evidencia o transporte seletivo de partículas - processo regulado pelo relevo (Haan et al., 1994). O grupo 4 aparece com grande teor de argila e teor muito baixo de areia fina, seguindo o padrão hidrográfico da área, concentrando-se em áreas úmidas. O grupo 5 apresenta teor bastante alto de matéria orgânica, seguido de areia grossa, aparecendo em áreas próximas à zona urbana, o que evidencia presença de detritos orgânicos oriundos dessas áreas. A taxa de perda de solo depende da facilidade de desprendimento e transporte de partículas, estando em função principalmente da textura e matéria orgânica, além da estrutura e permeabilidade (Toy et al., 2002). A topografia influencia na distribuição espacial da granulometria, sendo a distribuição superficial dependente da direção do fluxo de água e do manejo (Souza et al., 2003; Sanchez et al., 2005; Leão et al., 2010). Além disso, a remoção de partículas de solo difere de acordo com a forma da vertente, o que condiciona a variabilidade de seus atributos físicos (Souza et al., 2004).

A análise de componentes principais discriminou as variáveis segundo as propriedades do solo em cada amostra, porém em menores dimensões em relação à análise de agrupamento. Foram considerados os quatro primeiros autovalores obtidos da matriz de covariância dos dados originais, que determinaram as combinações lineares das variáveis originais, isto é, os componentes principais. No quadro 2 é possível observar as correlações das variáveis e dos componentes principais.

Os quatro primeiros componentes principais retêm $87,42 \%$ das informações, tendo o primeiro componente principal (CP1) 35,90 \% da variância total; o segundo (CP2), 23,48 \%; o terceiro (CP3), 15,14\%; e o quarto (CP4), 12,89\%. Diversos estudos utilizaram a análise de componentes principais na discriminação de áreas de manejo e classes de solos envolvendo características químicas e físicas com autovalores acima de $70 \%$ e reduzido número de componentes principais, com resultados satisfatórios (Melém Junior et al., 2008; Valladares et al., 2008; Lima et al., 2009).

No primeiro componente principal (Quadro 3), há evidência de transporte seletivo de partículas, pela correlação inversa do fator $\mathrm{K}$ (correlação negativa) com areia média, isto é, quanto maior o fator de erodibilidade, menor a quantidade de areia média; $\mathrm{e}$ correlação direta com silte e areia muito fina, mostrando que, quanto maior a quantidade dessas frações, maior a erodibilidade e efetividade do processo erosivo pelo desprendimento de partículas e transporte de material de frações menores (Haan et al., 1994). No segundo componente principal, a baixa coesão entre as partículas pode ser observada pela correlação inversa da areia grossa e fina, com a primeira diretamente correlacionada ao fator $\mathrm{K}$; para o terceiro componente, a maior agregação do solo é indicada pela correlação inversa do fator $\mathrm{K}$ com a argila, isto é, quanto maior a erodibilidade do solo, menor o teor de argila, aumentando a força de coesão entre as partículas e, consequentemente, a resistência à erosão (Toy et al., 2002). No quarto componente, a areia muito fina correlaciona-se inversamente com o fator $\mathrm{K}$ em áreas de acúmulo de sedimentos nas maiores cotas do relevo.

Quadro 3. Autovetores da matriz de correlação dos componentes principais (CP) e das variáveis argila, silte, matéria orgânica (MO), areia grossa $(\mathrm{AG})$, areia média $(\mathrm{AM})$, areia fina $(\mathrm{AF})$, areia muito fina (AMF) e fator $K$

\begin{tabular}{lrrrr}
\hline Variavel & CP1 & CP2 & CP3 & CP4 \\
\hline Argila & 0,580 & $-0,360$ & $\mathbf{0 , 6 5 9}$ & $-0,180$ \\
Silte & $\mathbf{0 , 6 0 2}$ & $-0,136$ & $-0,285$ & $-0,458$ \\
MO & 0,378 & $-0,435$ & $-0,558$ & $-0,342$ \\
AG & $-0,476$ & $\mathbf{- 0 , 7 5 5}$ & $-0,254$ & 0,251 \\
AM & $\mathbf{- 0 . 8 9 1}$ & $-0,355$ & $-0,002$ & $-0,090$ \\
AF & -0.444 & $\mathbf{0 , 7 6 1}$ & $-0,234$ & $-0,298$ \\
AMF & $\mathbf{0 , 6 7 3}$ & 0,175 & $-0,337$ & $\mathbf{0 , 6 1 9}$ \\
Fator K* & 0,559 & $-0,156$ & $-0,243$ & $-0,471$ \\
\hline
\end{tabular}

CP1: componente principal 1; CP2: componente principal 2; CP3: componente principal 3; CP4: componente principal 4; * variável suplementar.

\section{Quadro 2. Autovalores gerados da matriz de covariância}

Componentes principais (CP) Autovalores Variância total Autovalores acumulados Variância acumulada

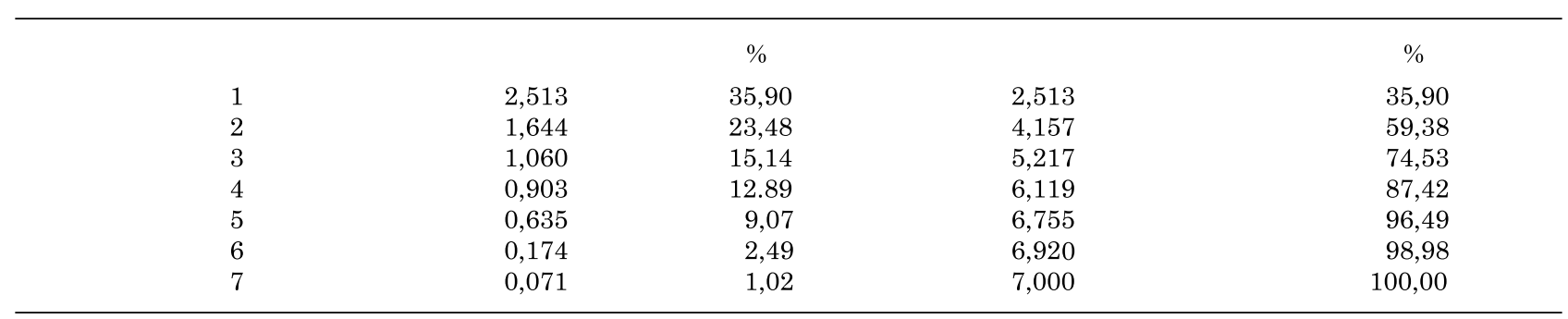


Os resultados da análise geoestatística dos semivariogramas, construídos por meio de modelos isotrópicos, os quais representaram da melhor maneira a distribuição espacial das variáveis, podem ser observados no quadro 4 e figura 3 . Todos os componentes principais foram ajustados pelo modelo exponencial.

A relação inversa da areia fina e areia grossa pode ter contribuído para o grande alcance do segundo componente principal, mais de $1.590 \mathrm{~m}$; os componentes restantes mantiveram um alcance entre 521 e $768 \mathrm{~m}$. Os dois últimos componentes refletem o comportamento da argila e areia muito fina, podendo indicar, com a proximidade de seus alcances, o caráter de limites próximos de tamanho de partículas entre essas frações granulométricas. $\mathrm{O}$ coeficiente de determinação $\left(R^{2}\right)$ dos modelos foi elevado, acima de $80 \%$, para todos os componentes principais. A soma dos quadrados dos resíduos (SQR) revelou menores resíduos para o segundo e terceiro componentes.
O índice de dependência espacial (IDE) para os quatro componentes foi classificado (Zimback, 2001) como moderado. Lima et al. (2009), utilizando o mesmo método de análise espacial dos componentes principais de atributos do solo em área de café, observaram que para os dois primeiros componentes, ajustados pelo modelo esférico discriminado pela acidez do solo, o IDE foi alto e moderado. Para o terceiro, com modelo exponencial e discriminado pelos macronutrientes, o IDE também foi moderado. Alvares et al. (2009), para solos com uso florestal na região de Capão Bonito-SP, observaram, para a camada superficial de solo, forte IDE para argila e areia total, IDE moderado para silte e IDE fraco para matéria orgânica.

Os mapas de isolinhas oriundos dos semivariogramas isotrópicos podem ser observados na figura 4. Os solos ricos em silte são facilmente erodíveis, uma vez que suas partículas tendem a proporcionar pequena adesão entre si (agregados), dificultando seu deslocamento; entretanto, destruídos esses agregados, pelo

Quadro 4. Modelos e parâmetros dos semivariogramas ajustados aos dados dos componentes principais

\begin{tabular}{llcrrrrr}
\hline Variavel & Modelo & Co & Co+C & a & $\mathbf{R}^{2}$ & SQR & IDE \\
\hline CP1 & Exponencial & 0,3098 & 0,980 & 521,00 & 0,840 & 0,012 & 0,684 \\
CP2 & Exponencial & 0,3490 & 0,860 & $1.593,00$ & 0,959 & 0,005 & 0,594 \\
CP3 & Exponencial & 0,2971 & 0,672 & 682,35 & 0,804 & 0,008 & 0,558 \\
CP4 & Exponencial & 0,4502 & 0,934 & 768,21 & 0,838 & 0,014 & 0,518 \\
\hline
\end{tabular}

Co: efeito pepita; Co+C: patamar; a: alcance (em metros); IDE: índice de dependência espacial (C/(Co+C)); $\mathrm{R}^{2}$ : coeficiente de determinação; SQR: soma dos quadrados dos resíduos.
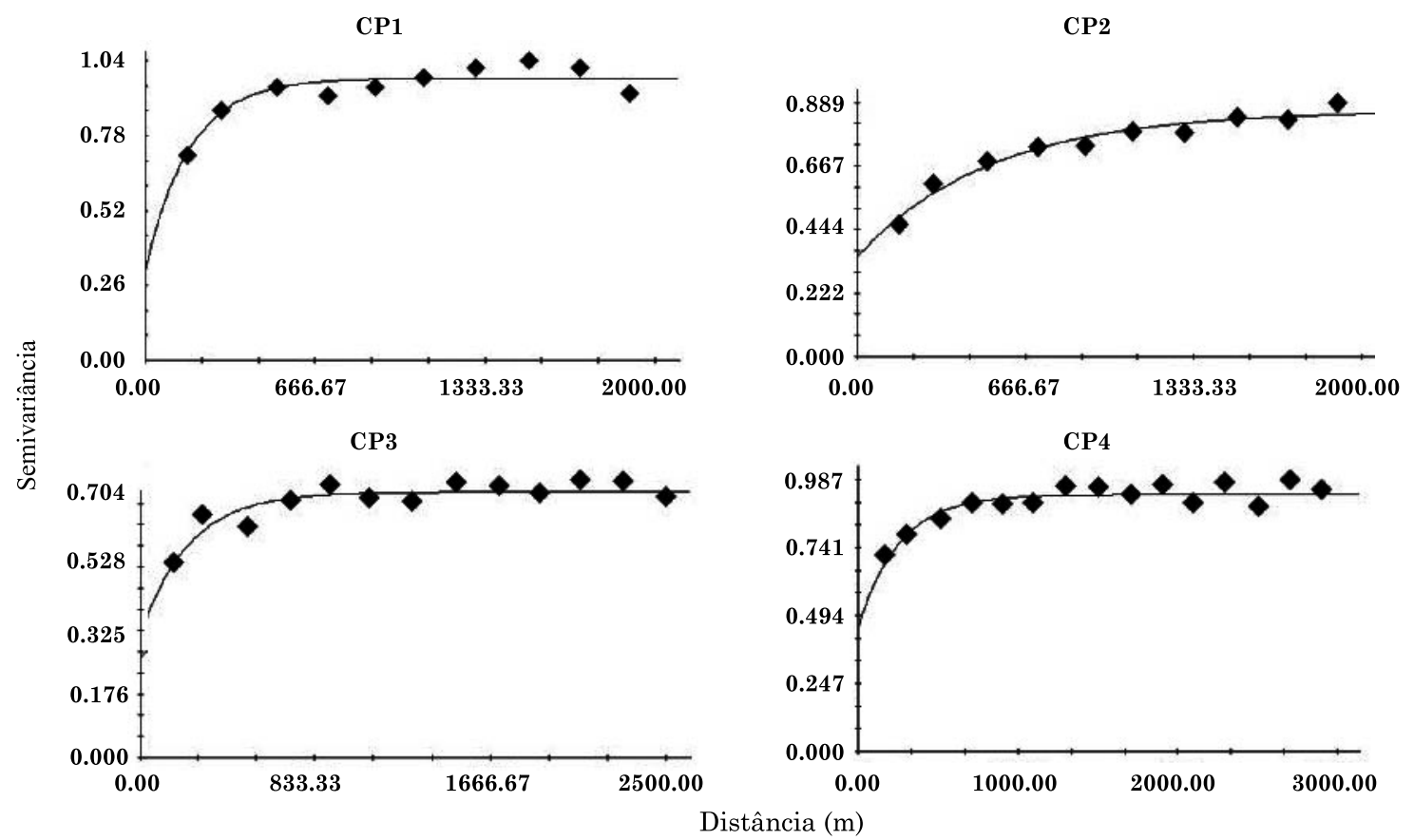

Figura 3. Semivariograma de cada componente principal (CP1: componente principal 1; CP2: componente principal 2; CP3: componente principal 3; CP4: componente principal 4). 

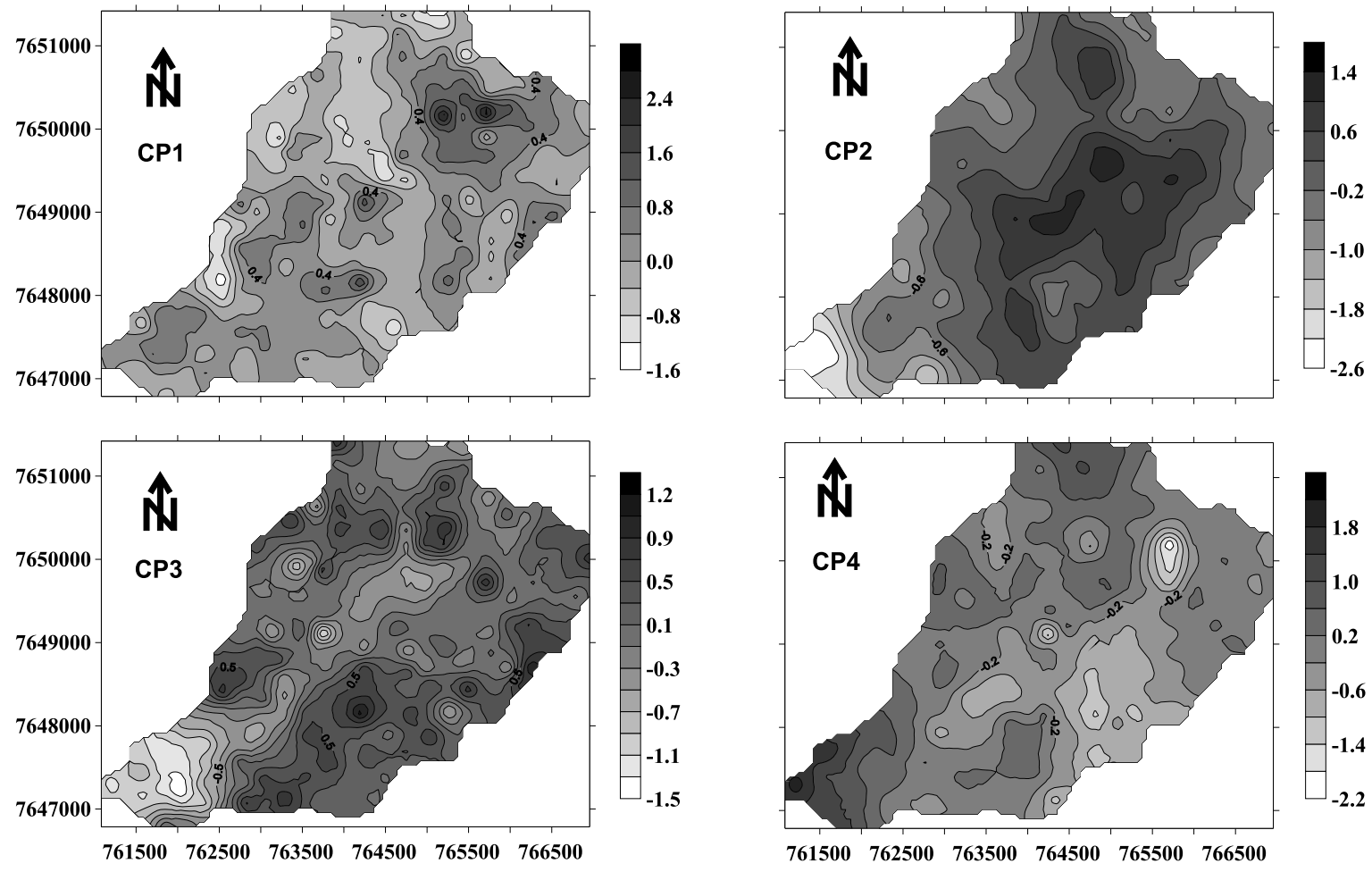

Figura 4. Distribuição espacial dos componentes principais ao longo do relevo (CP1: componente principal 1; CP2: componente principal 2; CP3: componente principal 3; CP4: componente principal 4) (Datum: UTM 22K Córrego Alegre Sul).

impacto das gotas de chuva, por exemplo, tornam-se mais leves para o transporte pela água. Isso também ocorre com as menores frações de areia, que são facilmente desagregadas pelas gotas de chuva e precisam de grande velocidade de enxurrada para seu arraste a longas distâncias (Bertoni \& Lombardi Neto, 2008). Dessa forma, os solos arenosos são muito permeáveis, porém, durante uma chuva, em razão do pequeno teor de matéria orgânica e argila, que fazem o ligamento das partículas, o escoamento superficial pode ocasionar grande perda de solo devido à baixa coerência entre as partículas (Toy et al., 2002).

Esses fatos evidenciam a distribuição espacial dos componentes principais. O primeiro componente principal, que se discrimina pelo transporte seletivo de partículas, mostra que sua maior concentração ocorre nas zonas pontuais de acúmulo de água, em zonas de maior declividade e acúmulo de sedimentos. O segundo componente, discriminado pela baixa coesão entre as partículas, mostra acúmulo de areia fina nas áreas de menor cota, em toda a área de concentração de água, também evidenciando o transporte das partículas menores e sedimentação. O terceiro componente, discriminado pela maior agregação do solo, concentra-se nas áreas de menor cota, principalmente nas bases de grandes declives. $\mathrm{O}$ quarto componente, discriminado pela areia muito fina, mostra uma distribuição ao longo das declividades, principalmente nas altitudes mais elevadas. Dessa forma, os resultados sugerem o comportamento granulométrico da área, que se mostra suscetível ao processo erosivo devido às condições texturais superficiais e à movimentação do relevo. A baixa resistência da superfície oriunda do caráter textura média e arenosa e a distribuição granulométrica da área favorecem um intenso processo de perda de solo com maior produção de sedimentos, o que está de acordo com o observado por Pissarra et al. (2006), que classificaram a área como de grande probabilidade de transporte de material em maior escala, com tendência de menor resistência à remoção de solo superficial.

\section{CONCLUSÕES}

1. A erodibilidade média estimada foi considerada alta, estando correlacionada com as variáveis granulométricas do solo e variando em áreas específicas de acordo com o relevo.

2. A análise de agrupamento e a de componentes principais forneceram componentes interpretáveis, sendo o primeiro relacionado ao transporte seletivo de partículas; o segundo, à baixa coesão entre as partículas; o terceiro, à agregação do solo; e o quarto, à areia muito fina.

3. A geoestatística de forma integrada com a análise multivariada auxiliou na compreensão do 
comportamento da erodibilidade em relação à granulometria e ao relevo da área.

\section{AGRADECIMENTO}

À Capes, pela bolsa concedida.

\section{LITERATURA CITADA}

ALVARES, C.A.; GONÇALVES, J.L.M.; SILVA, C.R.; FRANCISCATTE, W. \& NASCIMENTO, L.A. Variabilidade espacial dos solos florestais de Capão Bonito (SP). In: SIMPÓSIO DE GEOESTATÍSTICA APLICADA EM CIÊNCIAS AGRÁRIAS, Botucatu, 2009. Anais... Botucatu, FCA/UNESP, 2009. CD ROM.

BERTONI, J. \& LOMBARDI NETO, F. Conservação do solo. 6.ed. São Paulo, Ícone. 2008. 355p.

BUENO, C.R.P. \& STEIN, D.P. Potencial natural e antrópico de erosão na região de Brotas, Estado de São Paulo. Scientiarum, 26:1-5, 2004.

CANTARELLA, H.; QUAGgIO, J.A. \& RAIJ, B.van. Determinação da matéria orgânica. In: RAIJ, B.van; ANDRADE, C.; CANTARELLA, H. \& QUAGGIO, J.A., ed. Análise química para avaliação da fertilidade de Solos Tropicais. Campinas, Instituto Agronomico de Campinas, 2001. p.173-180.

DAY, P.R. Particle fractionation and particle-size analysis. In: BLACK, C.A., ed. Methods of soil analysis. Madison, American Society of Agronomy, 1965. p.545-566.

DENARDIN, J.E. Erodibilidade do solo estimada por meio de parâmetros físicos e químicos. Piracicaba, ESALQ/USP, 1990. 114p. (Tese de Doutorado)

EMPRESA BRASILEIRA DE PESQUISA AGROPECUÁRIA EMBRAPA. Centro Nacional de Pesquisa de Solos. Sistema brasileiro de classificação de solos. 2.ed. Rio de Janeiro, 2006. 306p.

HAAN, C.T.; BARFIELD, B.J. \& HAYES, J.C. Design hydrology and sedimentology for small catchments. San Diego, Academic Press, 1994. 578p.

HAIR, J.F, ANDERSON, R.E.; TATHAM, R.L. \& BLACK, W.C. Análise multivariada de dados, 5.ed. Porto Alegre, Bookman, 2005. 593p.

INSTITUTO DE PESQUISAS TECNOLÓGICAS DO ESTADO DE SÃO PAULO - IPT. Mapa Geológico do Estado de São Paulo. São Paulo, Divisão de Minas e Geologia Aplicada, 1, 126p. 1981. Escala 1:500.000. (IPT, Monografia, 6)

LEÃO, M.G.A.; MARQUES JUNIOR, J.; SOUZA, Z.M. \& PEREIRA, G.T. Variabilidade espacial da textura de um Latossolo sob cultivo de citrus. Ci. Agrotec., 34:121-131, 2010.

LIMA, J.S.S.; OLIVEIRA, R.B. \& SILVA, S.A. Estudo da fertilidade do solo em lavoura de café conilon utilizando análise multivariada e geoestatística. In: SIMPÓSIO DE GEOESTATÍSTICA EM CIÊNCIAS AGRÁRIAS, 2009, Botucatu. Anais... Botucatu, FCA/UNESP, 2009. CD ROM.
MELÉM JUNIOR, N.J.; FONSECA, I.C.B.; BRITO, O.R.; DECAËNS, T.; CARNEIRO, M.M.; MATOS, M.F.A.; GUEDES, M.C.; QUEIROZ, J.A.L. \& BARROSO, K.O. Análise de componentes principais para avaliação de resultados analíticos da fertilidade de solos do Amapá. Semina, 29:499-506, 2008.

PISSARRA, T.C.T.; BORGES, M.J.; GALBIATTI, J.A.; RODRIGUES, F.M. \& POLITANO, W. Análise morfométrica da microbacia hidrográfica do córrego rico, região nordeste do Estado de São Paulo. Cientifica, 34:170177,2006

SANCHEZ, R.B.; MARQUES JUNIOR, J.; PEREIRA, G.T. \& SOUZA, Z.M. Variabilidade espacial de propriedades de Latossolo e da produção de café em diferentes superfícies geomórficas. R. Bras. Eng. Agríc. Amb., 9:489-495, 2005.

SILVA, A.M. Potencial natural de erosão no município de Sorocaba, São Paulo, Brasil. R. Int. Desastres Nat., Accid. Infr. Civil, 8:5-14, 2008.

SOUZA, C.K.; MARQUES JUNIOR, J.; MARTINS FILHO, M.V. \& PEREIRA, G.T. Influência do relevo e erosão na variabilidade espacial de um Latossolo em Jaboticabal (SP). R. Bras. Ci. Solo, 27:1067-1074, 2003.

SOUZA, Z.M.; MARQUES JUNIOR, J.; PEREIRA, G.T. \& BENTO, M.J.C. Variabilidade espacial de atributos físicos de um Latossolo Vermelho sob cultivo de cana-de-açúcar. R. Bras. Eng. Agríc., 8:51-58, 2004.

SOUZA, Z.M.; MARTINS FILHO, M.V.; MARQUES JUNIOR, J.M. \& PEREIRA, G.T. Variabilidade espacial de fatores de erosão em Latossolo Vermelho eutroférrico sob cultivo de cana-de-açúcar. R. Bras. Eng. Agríc., 25:105-114, 2005.

TOY, T.J.; FOSTER, G.R. \& RENARD, K.G. Soil erosion: Processes, prediction, measurement, and control. New York, Willey, 2002. 338p.

TRANGMAR, B.B.; YOST, R.S. \& UEHARA, G. Application of geostatistics to spatial studies of soil properties. Adv. Agron., 38:54-94, 1985.

VALLADARES, G.S.; GOMES, E.G.; MELLO, J.C.C.B.S.; PEREIRA, M.G.; ANJOS, L.H.C.; EBELING, A.G. \& BENITES, V.M. Análise dos componentes principais e método multicritério ordinais no estudo de Organossolos e solos afins. R. Bras. Ci. Solo, 32:285-296, 2008.

VIEIRA, S.R. Geoestatística em estudos de variabilidade espacial do solo. In: NOVAIS, R.F.; ALVAREZ V., V.H. \& SCHAEFER, C.E.G.R., ed. Tópicos em ciência do solo. Viçosa, MG, Sociedade Brasileira de Ciência do Solo, 2000. v.1. p.1-54.

ZIMBACK, C.R.L. Análise espacial de atributos químicos de solos para fins de mapeamento da fertilidade. Botucatu, FCA/UNESP, 2001. 114p. (Tese de Livre-Docência) 